\title{
Assessment of spatio-temporal variability of rainfall and mean air temperature over Ardabil province, Iran
}

\author{
Mohammad Ali Ghorbani ${ }^{1,2}$ - Saba Mahmoud Alilou ${ }^{1} \cdot$ Sahar Javidan $^{1}$ · Sujay Raghavendra Naganna ${ }^{3}$ (i)
}

Received: 14 February 2021 / Accepted: 14 June 2021

Published online: 06 July 2021

(c) The Author(s) $2021 \quad$ OPEN

\begin{abstract}
Precipitation and temperature are the most important climate parameters, which vary both spatially and temporally. In the present study, rainfall data of 11 synoptic stations and 40 rain gauge stations and mean air temperature data of 11 synoptic stations of Ardabil province for the period 2009-2019 collected from the Meteorological Organization of Ardabil province, were considered for investigation. The descriptive statistics of rainfall and temperature such as mean, median, coefficient of variation, skewness and kurtosis were analyzed for monthly scale data. A higher coefficient of variation signified a greater degree of variation in precipitation and temperature data across different months. To evaluate the temporal stability over several months, Pearson linear correlation analysis at a significance level of $5 \%$ was performed for each variable. Kriging geostatistical estimator and GIS interface (ArcMap 10.4.1) were used for spatial interpolation with the aid of root mean square and SRMS standards. The results revealed that the spatial variation of temperature was greater than that of precipitation.
\end{abstract}

Keywords Spatiotemporal analysis $\cdot$ Kriging $\cdot$ Spatial dependence index $\cdot$ Coefficient of variation

\section{Introduction}

Precipitation and temperature are key meteorological parameters necessary for several hydro-climatological studies to identify the regional vulnerabilities due to global climate change. Indeed, precipitation is a key hydrologic variable that connects the atmosphere and land surface processes. Hence, the assessment of spatial variability of precipitation and temperature using appropriate methods is very much essential in the context of any pilot hydro-climatological study [23]. The precipitation in arid and semiarid climatic zones reflects great spatial and temporal variability due to wide swings in aerial temperature. The arid and semiarid environments dominate in Iran, which has eight distinct sorts of climatic zones as classified in Modarres and Sarhadi [22] based on factors such as proximity to the sea, elevation above mean sea level and the occurrence of the large atmospheric phenomenon such as subtropical highs. Agricultural productivity in dry lands depends on the total quantum of rainfall received in a season or a year as well as its distribution within that period [5]. Some of the methods used for the assessment of spatiotemporal variability of rainfall and temperature include geostatistics and classical statistics techniques [6]. In the analysis of 'developed data' through classical statistics, random variables are considered independent of each other, thus disregarding the influence between neighboring observations [27]. The spatial structure of rainfall (which is shown by the variogram) is highly variable depending on the type of climate and geography. It

Saba Mahmoud Alilou, saba.alilou.2016@gmail.com | 'Department of Water Engineering, Faculty of Agriculture, University of Tabriz, Tabriz, East Azerbaijan, Iran. ${ }^{2}$ Department of Civil Engineering, Istanbul Technical University, Istanbul, Turkey. ${ }^{3}$ Department of Civil Engineering, Siddaganga Institute of Technology, Tumakuru, Karnataka 572103, India.

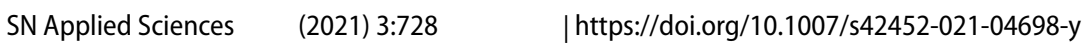


is also affected by accumulated precipitation over a time period. For example, a variogram which shows the spatial correlation of total daily rainfall is influenced by local weather conditions, while the monthly total rainfall is influenced by large-scale weather patterns [2].

Over time, extensive literature exists on the assessment of environmental variables and the analysis of climatic conditions and their spatial or temporal changes. Meduar et al. [20] studied the spatiotemporal variability of rainfall and the mean air temperature for the state of Bahia, Brazil, and concluded that climatic variables show a close relation between each other and their spatial and temporal variability was mostly dependent on seasons. Mostafavi et al. [24] analyzed the spatiotemporal precipitation distribution in Babolrood watershed using geostatistical methods and their analysis showed that across all the studied stations, the lowest rainfall was observed during June month; southern stations received most of the rainfall in October month and the middle and northern stations received the most rainfall during December month. Similarly, Javidan et al. [14] performed spatiotemporal analysis of precipitation in east Azarbaijan province using precipitation trends. The study concludes that there was increase in rainfall over $50 \%$ of the province area within the first month of each rainy season. Asakereh et al. [9] used the monthly precipitation data of 30 synchronous stations located in the northwestern Iran (1985-2014). Based on kriging interpolation technique fitted over the area, they concluded that the summer precipitation had a cluster behavior and spatial factors of altitude and slope significantly influenced on summer rainfall behavior of the region. Fadavi et al. $[12,16]$ evaluated and compared the error rates of different models in estimating the interpolation of daily minimum temperature in Isfahan province of two different years with different number of stations. This study concludes that, the increasing number of stations improves the accuracy of interpolation methods. Likewise, Askareh [6] used geostatistical methods for spatial analysis of precipitation over Iran. Hudson et al. [13] fit the points modeled on a $5 \mathrm{~km}$ square grid and concluded that the kriging method provides a fitted temperature estimate that correlates with height at weather stations. Siabi et al. [27] evaluated the combined geostatistical methods in increasing the accuracy of climatic classification and also zoning of climatic elements over northeastern Iran. Evaporation, altitude, relative humidity and rainfall were introduced as the most effective parameters in modeling temporal and spatial variability of climate over the study area. Mehdizadeh et al. [21] studied the efficiency of geostatistical methods in the climatic zoning of a drainage basin around Lake Urmia. They claim that geostatistical methods were better than the classic statistical methods. Khosravi et al. [16] classified the temperature and precipitation in
Iran using geostatistical methods and cluster analysis. The results showed that simple kriging method of exponential type and ordinary kriging method of spherical type were the best methods for the interpolation of precipitation and temperature. Karandish et al. [12,15] analyzed the accuracy of geostatistical methods along with preparing the spatial distribution maps of air temperature in mountainous areas and the analysis of monthly and annual isothermal maps by kriging method showed decrease in air temperature values from east to west.

Ardabil province in Iran is characterized by cool climate ( $\max 35^{\circ} \mathrm{C}$ ) even during the hot summer months and has the highest land use due to its climatic diversity among the provinces. Hence, the purpose of current study was to evaluate the spatiotemporal variability of rainfall of 11 synoptic stations and 40 rain gauge stations and mean air temperature of 11 synoptic stations of Ardabil province in the period 2009-2019.

\section{Materials and methods}

Ardabil province is a mountainous area, located in northwestern Iran between longitude ' $17^{\circ} 47$ to ' $55^{\circ} 48 \mathrm{E}$ and latitude ${ }^{\prime} 06^{\circ} 37$ to $' 42^{\circ} 39 \mathrm{~N}$. Except the Moghan plain in the northern part, the rest is covered by highs. With an area of $17,881 \mathrm{~km}^{2}$, this province covers 1.1 percent of the country's whole area. The highest and lowest annual rainfall in the province are 370 and $220.8 \mathrm{~mm}$, which belongs to Sarein and Namin stations, respectively. The annual rainfall average of the province is $347.5 \mathrm{~mm}$.

In the present study, to investigate the spatiotemporal variability of temperature, 11 synoptic stations of Ardabil province namely, the Ardabil airport, Ardabil, Parsabad, Khalkhal, Meshkinshahr, Sarein, Bilesvar, Garmi, Firoozabad, Namin and Nir, were selected to investigate the spatiotemporal variability of temperature, and for rainfall, in addition to 11 synoptic stations, 40 rain gauge stations were selected. The location of selected stations is shown in Fig. 1. Daily data of precipitation and mean air temperature were obtained from the Meteorological Organization of Ardabil province. The data period varied across a number of regional meteorological stations; therefore, only 11 years (2009-2019) data have been selected as a common period between all stations and finally converted into monthly data.

To analyze the monthly descriptive statistics of precipitation and mean air temperature, statistical characteristics like mean and median were used to determine the position measurement; coefficient of variation was utilized to determine the dispersion; and skewness and 
Fig.1 Distribution of studied stations

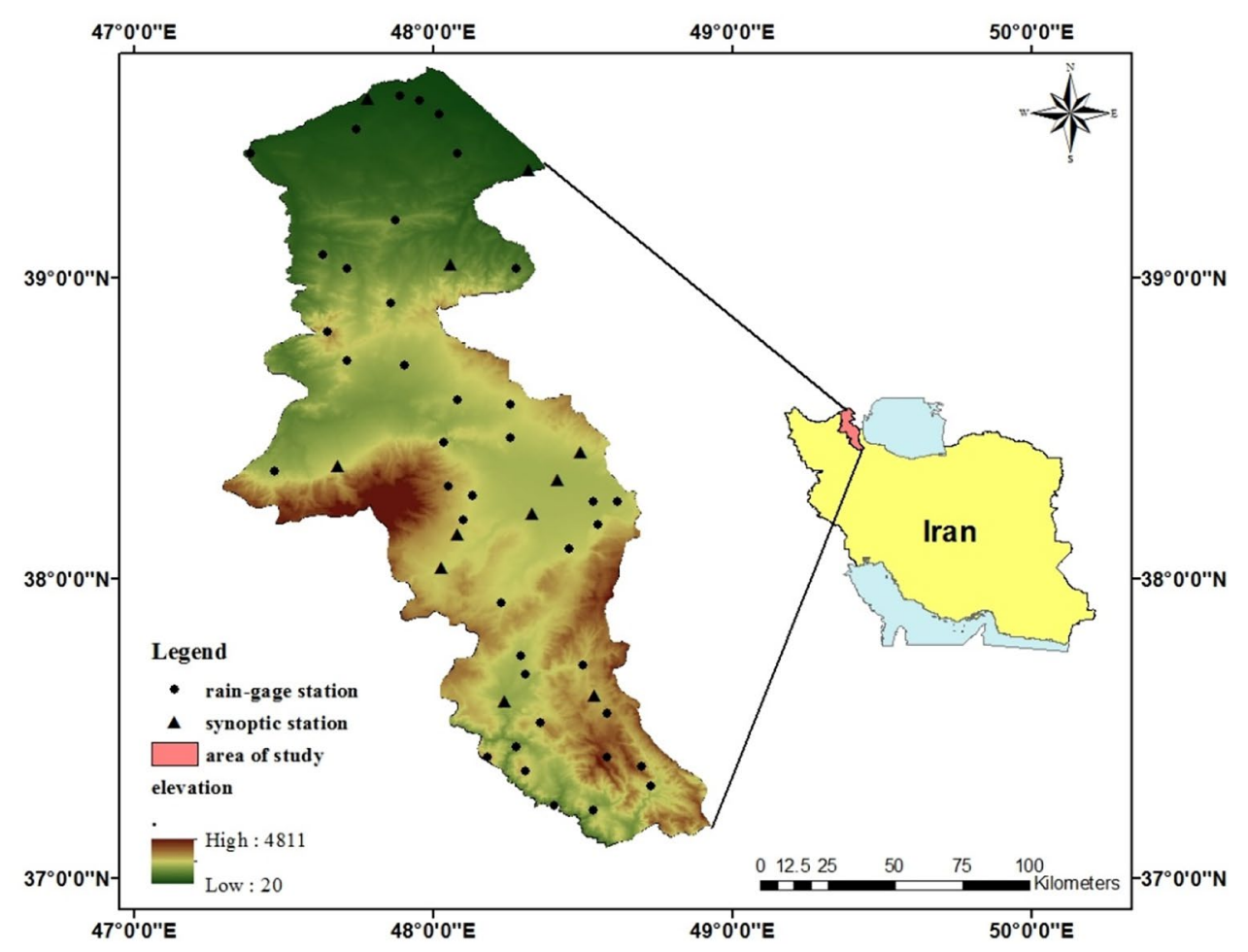

kurtosis were employed to determine the shape of the dispersion.

Equations 1, 2, 3, 4 and 5 show how to calculate the dispersion, skewness and kurtosis coefficients [18]

$C_{v}=\frac{S}{\bar{X}}$

$\mu_{3}=\frac{1}{N} \sum\left(x_{i}-\bar{x}\right)^{3}$

$C_{s}=\frac{\mu_{3}}{S^{3}}$

$\mu_{4}=\frac{1}{N} \sum\left(x_{i}-\bar{x}\right)^{4}$

$C_{k}=\frac{\mu_{4}}{S^{4}}$

where $C_{v}$ is the coefficient of variation, $S$ is the standard deviation, $\bar{X}$ denotes data mean, $\mu_{3}$ denotes third moment around the average, $\mu_{4}$ denotes fourth moment about the mean, $x_{i}$ is the respective count of data, $N$ denotes number of data points, $C_{s}$ is the skewness coefficient and $C_{k}$ denotes kurtosis coefficient. In order to check the temporal stability over the months, Pearson linear correlation analysis for each variable at the level of $5 \%$ probability was performed using XLSTAT 2016 software. Kriging method is based on quantitative measure of regionalized variable theory. It is the best nonlinear estimator as the variance of the estimate would be minimal and without any systematic error. The main advantages of kriging estimation include absoluteness in interpolation of points with a measure of the probable error linked with the estimates [24]. In all interpolation methods, the results are calculated from the weighted average of the available data, so that the least standard deviation is achieved. The rate of deviation of spatial points is determined by 'Semivariogram,' which is a function that calculates half the sum of squares of the difference in values [19]. Kriging interpolation depends on describing accurately the change in spatial correlation with distance.

Equation (6) shows the general kriging relationship:

$Z^{*}=\sum_{i=1}^{N} \lambda_{i} Z\left(x_{i}\right)$

where $N$ is number of data, $Z^{*}$ is the estimate of spatial data, $Z\left(x_{i}\right)$ is the magnitude of observed data at the point $\mathrm{i}, \lambda_{i}$ is the sample weight of $x_{i}$ which shows the importance of point $i$ in kriging calculations, and the sum of the $\lambda_{i}$ coefficients will be equal to 1 . Kriging is an unbiased estimator with lowest estimation of variance. The values of the samples depend on their position, Therefore, in order to be able to use geostatistical methods, the existence of spatial correlation between data is examined. The criterion relation of the experimental Semivariogram $\gamma$ is as follows [17]: 
$\gamma(h)=\frac{1}{2 n(h)} \sum_{i=1}^{n(h)}\left[Z\left(x_{i}\right)-Z\left(x_{i}+h\right)^{2}\right]$

shown in Eq. (7), $\gamma(\mathrm{h})$ is the value of experimental Semivariogram at $h$ distance, $n(h)$ is the number of pairs of points in a particular class of distance and direction, $x_{i}$ and $h+x_{i}$ are sampling locations that separated by $h$, and $Z\left(x_{i}\right)$ and $Z\left(x_{i}+h\right)$ are the measured values of the $Z$ variable in the mentioned place. Semivariogram is a function of distance and direction, so for variables that depend on direction (anisotropic spatial pattern) can be used [29].

In the kriging system, the experimental discontinuous variogram must be replaced by a theoretical continuous variogram. For this purpose, exponential and Gaussian models have been used and the relationships of which are given (8 and 9), respectively:

$\gamma(h)=c \cdot \operatorname{Exp}\left(\frac{h}{r}\right)=c \cdot\left[1-\exp \left(-\frac{h}{r}\right)\right]$

$\gamma(h)=c \cdot\left[1-\exp \left(-\frac{h^{2}}{r^{2}}\right)\right]$

which are given in Eqs. 8 and 9, respectively, $C$ is the upper limit and $r$ is the range of quasi-variogram.

To analyze the spatial dependence index (SDI), Eqs. 10 and 11 for the exponential and Gaussian models were used.

$\mathrm{SDI}_{\text {Exponential }}(\%)=0.317 \times\left(\frac{C}{C_{0}+C}\right) \times\left(\frac{a}{0.5 M D}\right) \times 100$

$\mathrm{SDI}_{\text {Gaussian }}(\%)=0.504 \times\left(\frac{C}{C_{0}+C}\right) \times\left(\frac{a}{0.5 M D}\right) \times 100$

$C_{0}$ is the nugget effect, $C_{0}+C$ is the sill, $a$ is the range and $\mathrm{MD}$ is the maximum distance between sampling points. Spatial dependence index is considered as strong for (SDI $<25)$; moderate for $(25 \% \leq \mathrm{SDI}<75 \%)$; and weak for (SDI $\geq 75 \%)$ [10]. To select the best variogram for each month, root mean square (RMS) and standardized root mean square (SRMS) criteria were used according to Eqs. 12 and 13.

$$
\begin{aligned}
& \mathrm{RMS}=\sqrt{\frac{1}{n} \sum_{i=1}^{n}\left(Z\left(x_{i}\right)-\hat{Z}\left(x_{i}\right)\right)^{2}} \\
& \mathrm{SRMS}=\sqrt{\frac{1}{n} \sum_{i=1}^{n} \frac{\left(Z_{0}-Z_{p}\right)^{2}}{S^{2}}}
\end{aligned}
$$

In the above relations, ' $n$ ' is number of points, $Z\left(x_{i}\right)$ is the actual amount of information at point $x_{i}, \hat{Z}\left(x_{i}\right)$ is the information estimated and $S$ is the variance. The best estimate for variogram would be least RMS and SRMS close to 1. RMS can be estimated in all local expressive methods, but SRMS can only be calculated and estimated in the kriging method [11].

\section{Results and discussion}

The present study utilized rainfall data of 11 synoptic stations and 40 rain gauge stations and mean air temperature data of 11 synoptic stations of Ardabil province for the period 2009-2019. The statistical characteristics of the mentioned parameters in the studied stations are presented in Table 1. The proximity of the mean and median values to each other, and also the proximity of the skewness coefficient to zero and the kurtosis coefficient to 3 , shows the symmetric distributions. There was an absence of the mentioned conditions for the monthly data of this study indicating that the values of the monthly mean are asymmetric.

Table 1 Statistical characteristics of meteorological parameters

\begin{tabular}{|c|c|c|c|c|c|}
\hline Month & $\mathrm{Ck}$ & Cs & $\mathrm{Cv}(\%)$ & Median & Mean \\
\hline \multicolumn{6}{|l|}{ Rainfall (mm) } \\
\hline January & -0.70 & -0.08 & 45 & 51.01 & 47.07 \\
\hline February & -0.64 & 0.49 & 32 & 30.89 & 33.80 \\
\hline March & 0.37 & 0.60 & 30 & 38.06 & 38.24 \\
\hline April & 10.54 & 2.51 & 29 & 42.19 & 42.24 \\
\hline May & 11.82 & 2.91 & 38 & 37.94 & 40.06 \\
\hline June & 2.86 & 1.23 & 49 & 20.19 & 22.47 \\
\hline July & 3.04 & 1.76 & 75 & 6.00 & 8.08 \\
\hline August & -0.48 & 0.65 & 68 & 8.00 & 9.40 \\
\hline September & -0.63 & 0.69 & 58 & 17.23 & 20.88 \\
\hline October & -0.42 & 0.47 & 30 & 36.72 & 36.98 \\
\hline November & 0.73 & 0.93 & 39 & 24.01 & 23.94 \\
\hline December & -0.69 & 0.28 & 32 & 26.92 & 28.43 \\
\hline \multicolumn{6}{|c|}{ Mean air temperature $\left({ }^{\circ} \mathrm{C}\right)$} \\
\hline January & 2.2 & 0.35 & 155 & 0.71 & 1.44 \\
\hline February & 2.04 & 0.33 & 86 & 2.19 & 2.34 \\
\hline March & 1.7 & 0.29 & 29 & 6 & 6.56 \\
\hline April & 1.58 & 0.42 & 19 & 9.7 & 0.63 \\
\hline May & 2.51 & 0.89 & 15 & 15.63 & 16.52 \\
\hline June & 2.39 & 0.88 & 16 & 19.55 & 20.7 \\
\hline July & 2.29 & 0.83 & 15 & 21.08 & 22.76 \\
\hline August & 2.37 & 0.87 & 15 & 20.27 & 21.87 \\
\hline September & 2.55 & 0.93 & 15 & 17.25 & 18.01 \\
\hline October & 2.65 & 0.74 & 16 & 12.29 & 12.78 \\
\hline November & 3.04 & 0.51 & 31 & 6.43 & 6.46 \\
\hline December & 2.5 & 0.29 & 73 & 2.58 & 2.95 \\
\hline
\end{tabular}
used 
According to the classification presented by Warik and Nelson [33], Cv $<12 \%$ shows small changes, $12 \%<\mathrm{Cv}<$ $60 \%$ moderate and $C v>60 \%$ high.

According to the Cv values in Table 1, July and August have a lot of changes and other months have moderate changes; the most and the least changes are related to the months of August and April, respectively. The mean temperature varies moderately from March to November and varies widely in January, February and December. The high coefficient of variation indicates the disorder and unpredictability of the parameters in different months and the less coefficient of variation, indicates stability and uniform time distribution.

Silva et al. [30] with using Uberaba-MG data confirmed that $\mathrm{Cv}$ is moderate to high for rainfall and stated that the lack of rainfall in some years of this series in the dry season may explain the variations. The results of the present study are in accordance with the study of Mostafazadeh and Mehri [25], so that they estimated the coefficient of change as medium in the central part of Ardabil by evaluating the changes in the seasonal precipitation index. This assessment shows a uniform decrease in precipitation in different months which can be related to the effect of elevation and the source of precipitation of the region.

The results of Pearson correlation analysis between the monthly mean of the studied variables are presented in Table 2. Pearson correlation coefficient is numerically between -1 and +1 , The correlation between 0 and 1 shows a positive correlation and that between -1 and 0 shows a negative correlation and how much these values being closer to 1 or -1 , their correlation would be stronger.

When evaluating the behavior of variables between different months of the years, the difference between the monthly mean is observable. November, September and April rainfall has a negative correlation which means low spatial continuity and temporal stability manner, and due to the correlations with values close to zero, this type of inverse correlation will be weak. In other months, the correlations are positive and direct. For the mean air temperature, there is no negative correlation between the months. The results of Mousavi's study [26] showed that the mean of annual temperature in Ardabil station does not have a significant trend, but the annual rainfall trend is significant and has a downward trend.

Table 2 Pearson linear correlation analysis

\begin{tabular}{|c|c|c|c|c|c|c|c|c|c|c|c|c|}
\hline Month & January & February & March & April & May & June & July & August & September & October & November & December \\
\hline \multicolumn{13}{|l|}{ Rainfall } \\
\hline January & 1 & 0.691 & 0.690 & 0.614 & 0.287 & 0.344 & 0.625 & 0.303 & 0.272 & 0.417 & 0.041 & 0.731 \\
\hline February & & 1 & 0.787 & 0.550 & 0.220 & 0.327 & 0.639 & 0.361 & 0.345 & 0.500 & 0.334 & 0.693 \\
\hline March & & & 1 & 0.816 & 0.465 & 0.357 & 0.634 & 0.183 & 0.120 & 0.422 & 0.457 & 0.718 \\
\hline April & & & & 1 & 0.725 & 0.480 & 0.591 & 0.077 & -0.044 & 0.256 & 0.293 & 0.535 \\
\hline May & & & & & 1 & 0.752 & 0.554 & 0.370 & 0.169 & 0.272 & 0.173 & 0.197 \\
\hline June & & & & & & 1 & 0.685 & 0.639 & 0.573 & 0.435 & -0.031 & 0.054 \\
\hline July & & & & & & & 1 & 0.630 & 0.562 & 0.549 & 0.256 & 0.413 \\
\hline August & & & & & & & & 1 & 0.752 & 0.673 & 0.093 & 0.158 \\
\hline September & & & & & & & & & 1 & 0.694 & 0.020 & 0.133 \\
\hline October & & & & & & & & & & 1 & 0.437 & 0.515 \\
\hline November & & & & & & & & & & & 1 & 0.469 \\
\hline December & & & & & & & & & & & & 1 \\
\hline \multicolumn{13}{|c|}{ Mean air temperature } \\
\hline January & 1 & 0.945 & 0.880 & 0.825 & 0.773 & 0.732 & 0.696 & 0.699 & 0.645 & 0.784 & 0.911 & 0.967 \\
\hline February & & 1 & 0.975 & 0.944 & 0.853 & 0.827 & 0.802 & 0.800 & 0.753 & 0.862 & 0.911 & 0.888 \\
\hline March & & & 1 & 0.982 & 0.910 & 0.892 & 0.875 & 0.870 & 0.835 & 0.911 & 0.903 & 0.824 \\
\hline April & & & & 1 & 0.915 & 0.915 & 0.911 & 0.898 & 0.866 & 0.908 & 0.859 & 0.768 \\
\hline May & & & & & 1 & 0.994 & 0.977 & 0.983 & 0.978 & 0.992 & 0.933 & 0.799 \\
\hline June & & & & & & 1 & 0.993 & 0.995 & 0.987 & 0.979 & 0.898 & 0.756 \\
\hline July & & & & & & & 1 & 0.997 & 0.983 & 0.955 & 0.855 & 0.711 \\
\hline August & & & & & & & & 1 & 0.990 & 0.965 & 0.872 & 0.728 \\
\hline September & & & & & & & & & 1 & 0.970 & 0.861 & 0.696 \\
\hline October & & & & & & & & & & 1 & 0.952 & 0.823 \\
\hline November & & & & & & & & & & & 1 & 0.948 \\
\hline December & & & & & & & & & & & & 1 \\
\hline
\end{tabular}


The results of study and analysis of temporal-spatial changes of precipitation and temperature of Ardabil station using Pearson method illustrate that there was a direct and very small connection between the two parameters, and in a low extent, $0.08 \%$ of precipitation changes were associated with temperature. Finally, Pearson linear correlation coefficient demonstrated that at the level of $95 \%$ confidence, there is no significant relationship between temperature and precipitation in Ardabil [31].

The kriging geostatistical method was used to evaluate the spatial distribution of precipitation and mean air temperature. The models and parameters of variogram are given in Table 3. Exponential and Gaussian variograms have been used in the present study. For each month, a variogram was selected which had a lower RMSE and a SRMSE close to 1. For rainfall, except for three months and for the mean air temperature, except for four months exponential model was selected as the best model.

In the results of [1] article, for spatial zoning of precipitation and temperature using spatial statistics methods in the north of Ardabil province, the best variogram model was the Gaussian model and the data have a strong spatial structure.
The amount of the nugget value $\left(C_{0}\right)$ in all variograms is very low, compared with the sill value $\left(C_{0}+C\right)$. The amount of $\mathrm{C}_{0}$ in rainfall and the mean air temperature, respectively, are from 0 to 0.62 and 0 to $0.37 \mathrm{~m}^{-2}$. The value of the range (a) is an important parameter of the variogram and represents the distance between two points, where there is a spatial dependence [4]. The value of (a) for precipitation and mean air temperature varies from 118.74 to $550.56 \mathrm{~km}$ and 128.41 to $194.07 \mathrm{~km}$, respectively. The high range of the variogram indicates a low spatial variability because the impact area increases and the similarity between neighboring points and thus the spatial continuity also increases. The highest values of (a) for precipitation were in November, but temperature had a smaller range, which means that the spatial variation for the temperature parameter is greater than precipitation.

The high amount of range and coefficient of variation and also standard deviation are an emphasis on large changes in precipitation in the location and instability and uncertainty of the amount of precipitation received. The existence of maximum precipitation is due to the effect of spatial factors such as high altitude and latitude on the occurrence [8].
Table 3 Models and parameters of variogram for monthly mean rainfall and mean air temperature

\begin{tabular}{lcllllll}
\hline Month & SDI(\%) & SRMS & RMS & $\mathrm{a}(\mathrm{km})$ & $\mathrm{C}_{0}+\mathrm{C}\left(\mathrm{m}^{-2}\right)$ & $\mathrm{C}_{0}\left(\mathrm{~m}^{-2}\right)$ & Model \\
Rainfall & & & & & & & \\
January & 9.63 & 1.08 & 20.33 & 144.61 & 0.7 & 0.5 & Exp \\
February & 11.87 & 1.09 & 9.75 & 148.95 & 0.79 & 0.62 & Gau \\
March & 8.82 & 0.95 & 9.98 & 118.74 & 0.69 & 0.47 & Exp \\
April & 18.31 & 0.92 & 10.09 & 119.92 & 0.87 & 0.3 & Exp \\
May & 69.63 & 0.91 & 15.09 & 298.86 & 1.17 & 0 & Exp \\
June & 6.27 & 1.3 & 9.33 & 185 & 0.55 & 0.47 & Exp \\
July & 48.24 & 1.09 & 5.7 & 207.07 & 0.85 & 0 & Exp \\
August & 9.14 & 1.12 & 5.44 & 144.61 & 0.59 & 0.43 & Exp \\
September & 35.28 & 1.01 & 6.8 & 159.58 & 0.62 & 0.25 & Gau \\
October & 60.93 & 0.98 & 9.97 & 261.5 & 0.95 & 0 & Exp \\
November & 15.69 & 1.02 & 8.85 & 550.56 & 0.65 & 0.6 & Gau \\
December & 11.15 & 0.98 & 8.16 & 134.97 & 0.79 & 0.51 & Exp \\
Mean air temperature & & & & & & \\
January & 74.56 & 0.93 & 1.19 & 194.07 & 1.43 & 0.17 & Gau \\
February & 54.89 & 1.13 & 1.54 & 161.44 & 1.09 & 0.24 & Gau \\
March & 44.03 & 1.2 & 1.73 & 160.56 & 1.38 & 0 & Exp \\
April & 54.40 & 1.19 & 1.63 & 166.8 & 1.27 & 0.32 & Gau \\
May & 39.09 & 1.21 & 2.29 & 166.8 & 1.1 & 0.16 & Exp \\
June & 45.74 & 1.12 & 2.82 & 166.8 & 1.35 & 0 & Exp \\
July & 45.74 & 0.93 & 2.67 & 166.8 & 1.38 & 0 & Exp \\
August & 45.74 & 1.02 & 2.69 & 166.8 & 1.4 & 0 & Exp \\
September & 36.63 & 1.09 & 2.46 & 128.41 & 1.07 & 0.37 & Gau \\
October & 34.83 & 1.11 & 1.99 & 166.8 & 1.09 & 0.26 & Exp \\
November & 41.45 & 1.11 & 1.84 & 163.19 & 1.22 & 0.09 & Exp \\
December & 42.57 & 1.01 & 1.61 & 160.56 & 1.2 & 0.04 & Exp \\
\hline
\end{tabular}


Spatial dependence index (SDI) has been used to examine the spatial dependence between the studied parameters and analysis according to the classification of Cambardella et al. [10]. According to the mentioned division, except for May, July, September and October which has a moderate spatial dependence, the other months of the rainfall parameter have a strong spatial dependence.

As for mean temperature, all months have moderate spatial dependence. The existence of spatial dependence geostatistics is vital for accurate mapping through kriging [32].
By analyzing rainfall maps (Fig. 2), it can be seen that the maximum rainfall with more than $111 \mathrm{~mm}$ occurs in May on the western part of the province and the minimum rainfall with less than $2 \mathrm{~mm}$ occurs in July on most area of the province. The precipitation temporal distribution is not uniform, and the maximum amounts of precipitation are generally concentrated in spring, early autumn and late winter.

According to Fig. 3, the warmest and coldest months are, respectively, in July and January, and in July, the eastern to northeastern parts and part of southwest of the
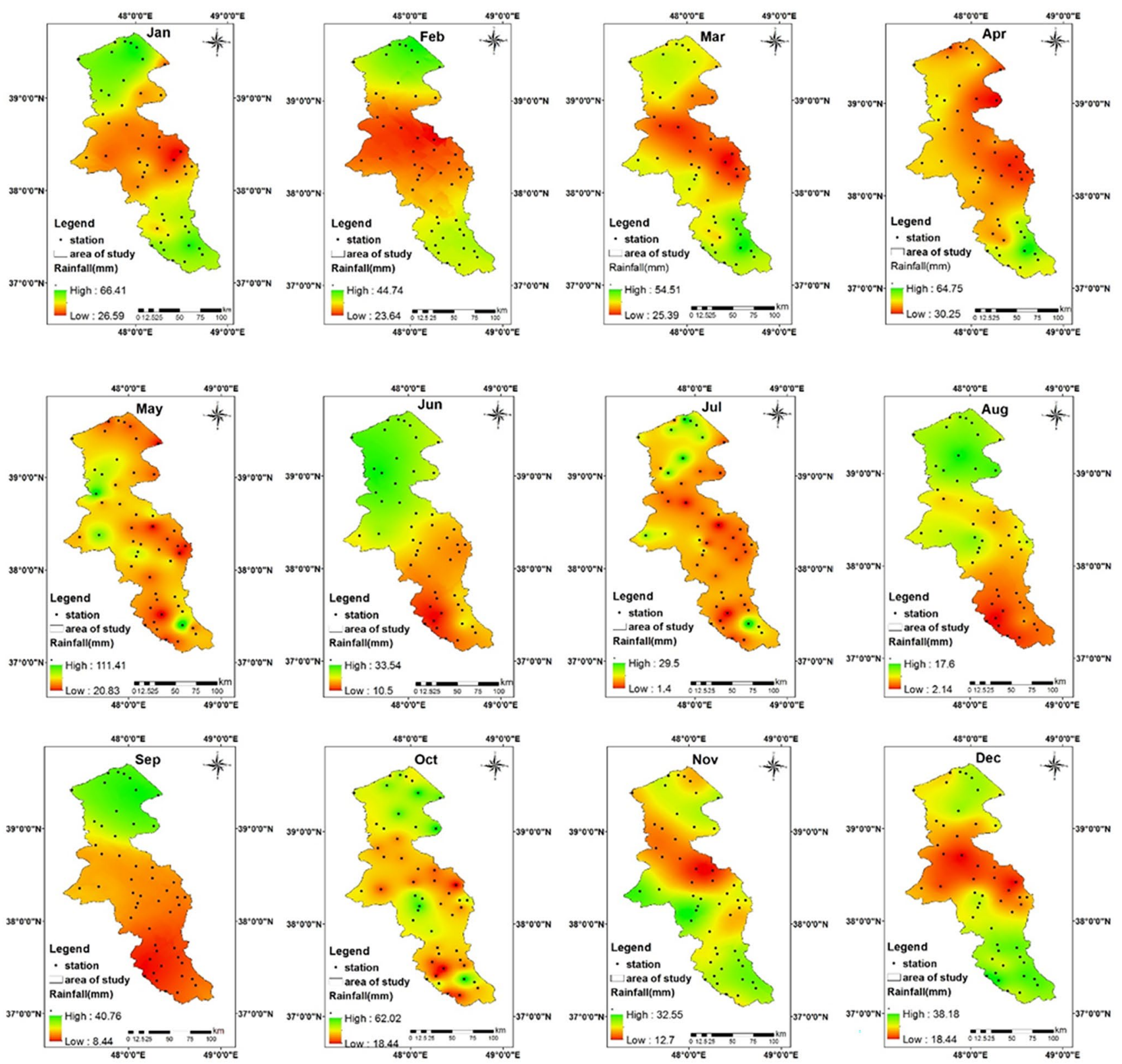

Fig. 2 Thematic rainfall maps of the time evolution month by month for Ardabil 

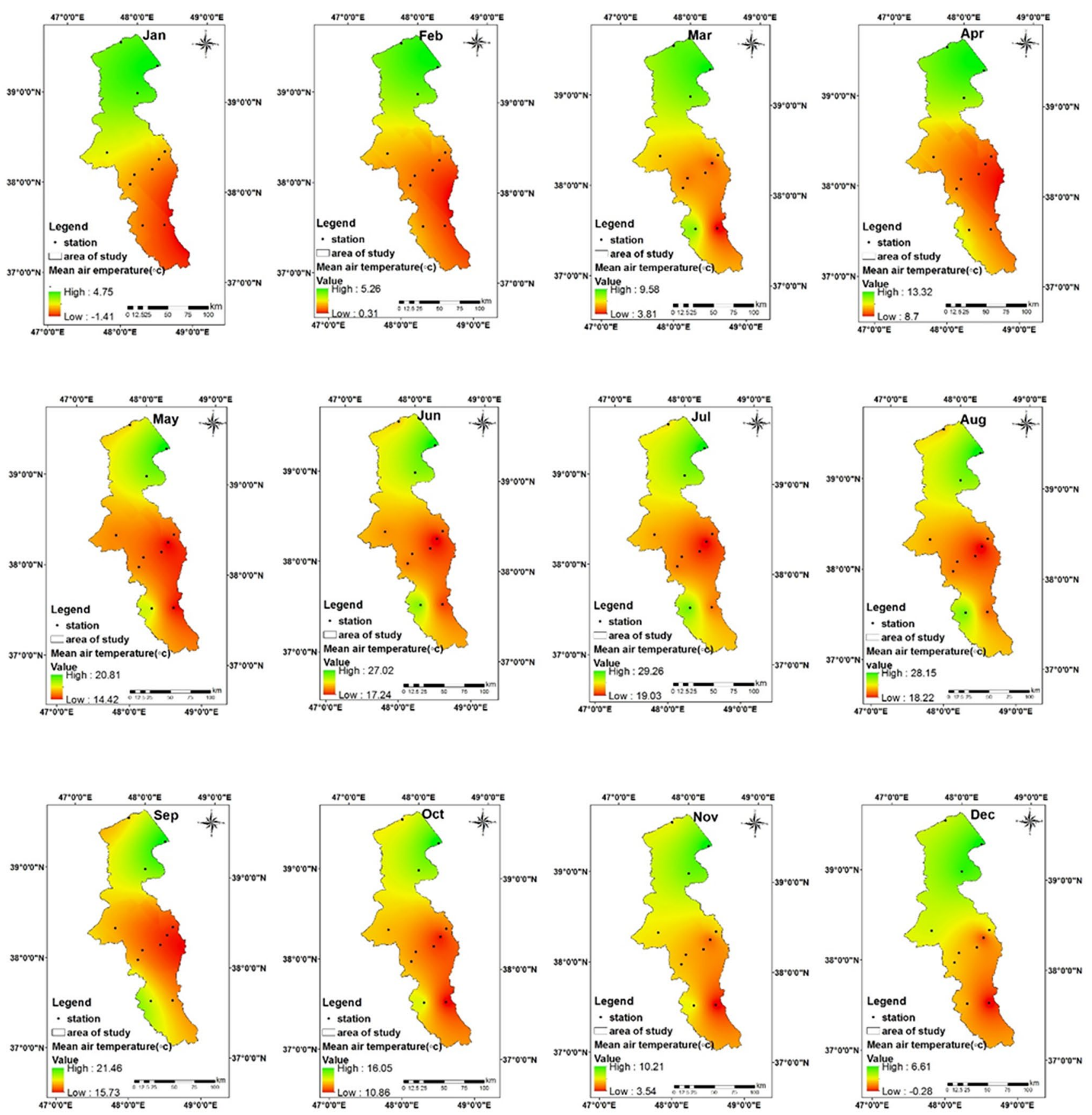

Fig. 3 Thematic temperature mean maps of the time evolution month by month for Ardabil

province have the highest temperature, and in January, the southern part of the province has the lowest temperature.

\section{Conclusions}

Rainfall and temperature are two of the most important climatic parameters. Recently, geostatistical methods play an important role in spatial mapping and aid in water resources planning. Geostatistical methods are suitable for the interpolation of the station information and examining spatial and temporal changes. Therefore, in the present study, spatiotemporal analysis was performed using kriging geostatistics technique based on meteorological data of rainfall of 11 synoptic stations and 40 rain gauge stations and mean air temperature of 11 synoptic stations of Ardabil province for the period 2009-2019. High coefficient of variation means low uniformity of rainfall and 
temperature in different months. Among used variograms in the present study (exponential and Gaussian), in most of the months due to less RMS and SRMS close to 1, the exponential model was selected as the best model, and according to the values of variogram range, the spatial variability of temperature was more than that of precipitation. The western part of the province received the most rainfall in May $(111 \mathrm{~mm})$. According to interpolation maps, July was the hottest and least rainy month.

\section{Declarations}

Conflict of interest The author declare that they have no conflict of interest.

Open Access This article is licensed under a Creative Commons Attribution 4.0 International License, which permits use, sharing, adaptation, distribution and reproduction in any medium or format, as long as you give appropriate credit to the original author(s) and the source, provide a link to the Creative Commons licence, and indicate if changes were made. The images or other third party material in this article are included in the article's Creative Commons licence, unless indicated otherwise in a credit line to the material. If material is not included in the article's Creative Commons licence and your intended use is not permitted by statutory regulation or exceeds the permitted use, you will need to obtain permission directly from the copyright holder. To view a copy of this licence, visit http://creativecommons. org/licenses/by/4.0/.

\section{References}

1. Alavinia F, Ghorbani A, Mohammadi Moghadam S, Sobhani B (2015) Precipitation and temperature zoning using spatial statistics methods in the north of Ardabil province. In: Third International Congress of earth, space \& clean energy

2. Ali A, Lebel T, Amani A (2003) Invariance in the Spatial Structure of Sahelian Rain Fields at Climatological Scales. Hydrometeorol J 4(6): 996-1011. https://doi.org/10.1175/1525-7541(2003)004\%3C0996: IITSSO\%3E2.0.CO;2

3. Alizadeh A (2010) Principles of Applied hydrology. $5^{\text {th }}$ ed. Imam Reza (AS) University, Mashhad

4. Almeida A, Souza R, Loureiro D, Pereira D, Cruz M, Vieira J (2017) Modelling the spatial dependence of the rainfall erosivity index in the Brazilian semiarid region. Pesq agropec bras 52(6):371-379. https://doi.org/10.1590/s0100-204×2017000600001

5. Arnon I (1992) Climatic Factors and their effect on Crop Production. In: Agriculture in Dry Lands, pp 39-83. https://doi.org/10. 1016/B978-0-444-88912-6.50006-2

6. Asakereh $\mathrm{H}$ (2007) Temporal-spatial changes of Iranian rainfall during the last decade. Geogr Dev 10:145-164

7. Asakereh $\mathrm{H}$ (2008) Usage of kriging method in rainfall detection. Geogr Dev 12:25-42

8. Asakereh H, HosseinJani L (2018) Spatial Autocorrelation of Annual Frequency of Heavy Rainfalls in Caspian Region. Phys Geogr Res Quarter 51(1):135-148

9. Asakereh $H$, Razmi $R$ (2018) Spatial modeling of summer rainfall in northwestern Iran. J Appl Res Geogr Sci 18:155-179

10. Cambardella C, Moorman T, Novak J, Parkin T, Karlen D, Turco R, Konopka A (1994) Field-scale variability of soil properties in central lowa soils. Soil Sci Soc Am J 58(5):1501-1511. https://doi.org/10. 2136/sssaj1994.03615995005800050033x
11. De Beurs K (1998) Evaluation of spatial interpolation techniques for climate variables: Case study of Jalisco, Mexico. MSc Thesis. Department of Statistics and Department of Soil Science and Geology, Wageningen Agricultural University, The Netherlands

12. Fadavi GH, Bazrafshan J, Ghahreman N (2015) Comparison of different regional estimation methods for daily minimum temperature (A case study of Isfahan province). J Agri Meteorol 2:14-23

13. Hudson G, Wackernagel $H$ (1993) Mapping temperature using kriging with external drift: Theory and an example from Scotland. Int J Climatol 14:77-79. https://doi.org/10.1002/joc.3370140107

14. Javidan S, Mikaeili F, Salarifard M, Fakheri Fard A (2019) Spatialtemporal analysis of precipitation in East Azerbaijan province using precipitation trends. 3rd Iranian National Conference on Hydrology

15. Karandish F, Ebrahimi K, Porhemmat J (2019) Increasing the accuracy of geostatistical assessments involving extrapolation and zonal classification techniques: case study of Karun basin daily rainfall, IRAN. Iran J Soil Water Res 50:713-724. https://doi.org/10. 22059/ijswr.2018.257870.667912

16. Khosravi M, Doustkamian M, Mirmousavi S, Biat A, Biek Rezaei E (2014) Classification of Temperature and Precipitation of Iran by using Geostatistical Methods and Cluster Analysis. Reg Plan J 4:121-132. https://www.sid.ir/en/journal/ViewPaper.aspx?id= 384341

17. Mahdian MH, Rahimi SB, Sokuti R, Banis YN (2009) Appraisal of the geostatistical methods to estimate monthly and annual temperature. J Appl Sci 9:128-134. https://doi.org/10.3923/jas.2009.128. 134

18. Manning JC (2016) Applied Principles of Hydrology, 3rd edn. Waveland Press, pp 276

19. McBratney A, Webster $R$ (1983) Optimal interpolation and isarithm mapping of soil properties. V. Coregionalization and multiple sampling strategy. Euro J Soil Sci 1:137-162. https://doi.org/10.1111/j. 1365-2389.1983.tb00820.x

20. Meduar CC, Samuel AS, Luis Carlos C, Ícaro M, Macedo G (2020) Spatial-temporal variability of rainfall and mean air temperature for the state of Bahia, Brazil. Ann Braz Acad Sci. https://doi.org/10. 1590/0001-3765202020181283

21. Mehdizadeh M, Mahdiyan H, Hajjam S (2007) The performance of Geostatistical methods in climate zoning of Lake Basin. J Earth Space Phy 1:103-116

22. Modarres R, Sarhadi A (2009) Rainfall trends analysis of Iran in the last half of the twentieth century. J Geophys Res Atmos 114:D03101. https://doi.org/10.1029/2008JD010707

23. Moradi HR, Rahdan H, Sharifi Kia M (2015) Investigation of changes and trends in rainfall and temperature in Isfahan. Water Extraction and Watershed Management Congress

24. Mostafavi R, Gholami Sh (2013) Spatial-temporal distribution analysis of precipitation using geostatistical method in Babolrood watershed. Iran J Nat Ecosyst 1:101-113

25. Mostafazadeh R, Mehri S (2018) Determination of the Precipitation Regime and the Seasonality Index Variations in the Central Part of the Ardabil province. Watershed Manag Res 120:29-39. https:// www.sid.ir/en/journal/ViewPaper.aspx?id=657014

26. Mir-Mousavi SH (2007) Investigation of temporal changes of temperature and precipitation in Ardabil meteorological station. 40-60

27. Santos E, Griebeler N, Oliveira L (2011) Variabilidade espacial e temporal da precipitação pluvial na bacia hidrográfica do Ribeirão João Leite-GO. Eng Agríc 31:78-89. https://doi.org/10.1590/S010069162011000100008

28. Seidel EJ, Oliveira MS (2016) A Classification for a Geostatistical Index of Spatial Dependence. Rev Bras Cienc Solo 40:e0160007. https://doi.org/10.1590/18069657rbcs20160007

29. Siabi N, Sanayinezhad SH (2013) Review of combined geostatistical methods in Increasing accuracy of climatic classification and 
zoning of climatic elements in northeastern Iran. J Climatol Res 15:82-92

30. Silva J, Guimarães E, Tavares M (2003) Temporal variability of monthly rains in the climatological station of Uberaba-MG, Brazil. Ciênc agrotec 27:665-674. https://doi.org/10.1590/S1413-70542 003000300023

31. Taran Z (2019) Review and analysis of spatio-temporal changes of climatic elements, Case study: Precipitation and temperature of Ardabil station. $2^{\text {nd }}$ International Conference on New Research in Civil Engineering, Architecture, Urban Management and Environment

32. Vieira, SR (2000) Geoestatística em estudos de variabilidade espacial do solo. In: Novais RF, Alvarez V (eds) Tópicos em ciência do solo. Viçosa, Sociedade Brasileira de Ciência do Solo, pp 1-54
33. Warrick A, Nielsen D (1980) Spatial variability of soil physical properties in the field. In: Hillel D (ed), Applications of soil physics. Academic Press, New york, pp 319-344

Publisher's Note Springer Nature remains neutral with regard to jurisdictional claims in published maps and institutional affiliations. 